\title{
Serious Psychological Distress and Emergency Room Use among Adults with Multimorbidity in the United States
}

\author{
Khalid Alhussain, ${ }^{1}$ Abdulkarim M. Meraya, ${ }^{2}$ and Usha Sambamoorthi ${ }^{1}$ \\ ${ }^{1}$ Department of Pharmaceutical Systems and Policy, School of Pharmacy, West Virginia University, P.O. Box 9510, \\ Morgantown, WV 26505, USA \\ ${ }^{2}$ Clinical Pharmacy Department, Faculty of Pharmacy, Jazan University, Jizan 45142, Saudi Arabia \\ Correspondence should be addressed to Khalid Alhussain; khalhussain@mix.wvu.edu
}

Received 17 May 2017; Revised 28 July 2017; Accepted 9 August 2017; Published 11 September 2017

Academic Editor: Nicola Magnavita

\begin{abstract}
Copyright (C) 2017 Khalid Alhussain et al. This is an open access article distributed under the Creative Commons Attribution License, which permits unrestricted use, distribution, and reproduction in any medium, provided the original work is properly cited.
\end{abstract}

Objectives. (1) To examine the association between serious psychological distress (SPD) and emergency room (ER) use in the past 12 months among adults with multimorbidity in the United States (US) and (2) to investigate the association between SPD and the reasons for ER use. Methods. The current study used a cross-sectional design with retrospective data from the 2015 National Health Interview Survey. Logistic regression models were used to assess the association between SPD and ER use among adults with multimorbidity. Among ER users, adjusted logistic regression models were conducted to examine the association between SPD and the reasons for the ER use. Results. After controlling for other variables, adults with multimorbidity and SPD were more likely to use ER than those with multimorbidity and no SPD ( $\mathrm{AOR}=1.61,95 \% \mathrm{CI}=1.26,2.04)$. Among ER users, there were no significant associations between SPD and the reasons for ER use after controlling for other variables. Conclusion. Adults with multimorbidity and SPD were more likely to use ER as compared to those with multimorbidity and no SPD. Among adults with multimorbidity, routine screening for SPD may be needed to reduce the ER use.

\section{Introduction}

The prevalence of multimorbidity, the coexisting of two or more chronic illnesses in the same individual has grown in the United States (US) [1]. In 2012, one in four civilian, noninstitutionalized US adults had multimorbidity [2]. Multimorbidity is associated with high healthcare utilization and cost $[3,4]$. It is also associated with poor physical function [5], poor health-related quality of life (HRQoL) [6], and poor mental health, specifically, serious psychological distress (SPD) $[7,8]$. Adults with multimorbidity are more likely to have SPD as previous studies showed $[7,8]$.

Multimorbidity as well as SPD has been shown to be associated with high healthcare utilization, especially, emergency room (ER) use [9-12]. Previous studies have indicated that multimorbidity was positively associated with ER use $[10,11]$. In a study assessing the association between multimorbidity and ER use, adults who had higher Charlson Comorbidity Index (CCI) scores were more likely to use the ER [11].
Further, there is a positive association between SPD and ER use $[9,12]$. One study using the 2004-2006 National Interview Health Survey data indicated that adults with SPD were 2.05 times as likely to use the ER as adults without SPD [12]. Another study using the 2007 Medical Expenditure Panel Survey data found that adults with SPD had higher ER visits than those without SPD [9].

However, no study has examined the use of ER among adults who suffer from both multimorbidity and SPD. Moreover, the reasons behind the possible association between SPD and ER use among adults with multimorbidity have not been investigated yet. Based on prior literature [9-12] we can speculate that adults with multimorbidity and SPD may be more likely to use ER because of the complexity of healthcare management as well as access issues. For example, adults with multimorbidity and SPD may use ER because of seriousness of their conditions. Therefore, the first objective of this study was to examine the association between SPD and ER use among US adults with multimorbidity and the second 
objective was to examine the association between SPD and the reasons for ER use.

\section{Methods}

2.1. Conceptual Framework. We used the expanded Andersen healthcare utilization model [13]. The purpose of this model is to demonstrate the factors that may lead to the use of ER. Based on this model, ER use may be influenced by five domains: predisposing factors (e.g., age and sex), enabling factors (e.g., education level and health insurance), need factors (e.g., SPD status and functional limitations), personal health practices (e.g., smoking status and alcohol use), and external environmental factors (e.g., the region of residence).

2.2. Study Design. We adopted a retrospective cross-sectional study using National Health Interview Survey (NHIS).

2.3. Data Source. The current study used data from 2015 NHIS, US nationally representative data. NHIS is an annual, cross-sectional survey among the civilian noninstitutionalized population of the US. To select the sample of dwelling units for the NHIS, multistage sampling techniques were used. Multistage methods divided the target universe into several nested levels of strata and clusters. This survey consists of two main sections, core and supplements. This study used data from the family, person, sample adult core, and imputed income files. Sociodemographic characteristics, health status, and health insurance were captured from the person file. Family file provided information about the poverty status of the household. The sample adult core file provided information about chronic physical conditions, psychological distress, access to care, and utilization of healthcare services [14].

2.4. Study Sample. The study sample was based on US adults aged $>21$ years having multimorbidity $(N=12,910)$. Multimorbidity was derived from the sample adult core file. It was defined as the presence of two or more of the following chronic physical conditions: arthritis, asthma, cancer, hepatitis, kidney disease, chronic obstructive pulmonary disease (COPD), diabetes, heart diseases (angina pectoris, coronary heart disease, heart attack, and other heart conditions), hyperlipidemia, hypertension, or stroke. The list of chronic conditions was adapted from a previous study [15]. We also excluded a few individuals with missing data in health insurance $(N=25)$ and ER use $(N=16)$. Thus, the final sample size consisted of 12,869 adults with multimorbidity.

\subsection{Measures}

\subsubsection{Dependent Variables}

(1) Emergency Room Use. ER use was self-reported and derived from the sample adult core file. Adults were asked, "During the past 12 months, how many times have you gone to a hospital ER about your own health?" Those who reported at least one ER visit were considered as "ER users."

(2) Reasons for the Most Recent ER Visit. Reasons for the most recent ER visit were extracted only for adults who had reported using ER in the past 12 months. In the NHIS, ER users were asked several questions about the reasons for their most recent ER visit. For this study, we categorized the reasons for the most recent ER visit into three categories based on a previous study [16]. First, the "lack of access to other providers" category included adults who selected at least one of the following reasons "did not have another place to go," "emergency room is the closest provider," or "get most of their care at the emergency room." Second, the "seriousness of the medical problem" category contained adults who reported one of the following reasons to visit ER: "health provider advised to go," "the problem was too serious for the doctor's office or clinic," "only a hospital could help," or "arrived by ambulance or another emergency vehicle." Third, the "doctor's office or clinic was not open" category included those who reported "doctor's office or clinic was not open." It has to be noted that respondents can provide multiple reasons for their recent ER visit.

2.5.2. Key Independent Variable: SPD Status (SPD or No SPD). SPD was measured by the Kessler-6 (K6) [17]. The K6 asks participants to assess the six symptoms of psychological distress over the past 30 days with a response scale ranging from 0 which is none of the time to 4 which is all of the time. The symptoms include feeling nervous, hopeless, restless or fidgety, so depressed that nothing could cheer you up, and worthless. The total K6 score ranges from 0 to 24, with higher scores indicating more severe psychological distress. A dichotomous variable indicating SPD or no SPD was constructed. Based on previous research, SPD was defined as a score of 13 or greater on the K6 since this cut-off is an indicator for mental illnesses [18].

2.5.3. Other Independent Variables. Predisposing factors included age (22-39 years, 40-49 years, 50-64 years, and 65 years and older), sex, and race/ethnicity (Hispanic, nonHispanic white, non-Hispanic black, and other non-Hispanic races). Enabling factors included marital status (married, widowed/divorced/separated, and never), education (less than high school, high school, and greater than high school), poverty status (poor (less than $100 \%$ federal poverty line), near poor $(100 \%$ to less than $200 \%)$, middle $(200 \%$ to less than $400 \%$ ), and high income (greater than or equal to $400 \%)$ ), and health insurance. Health insurance was defined as insured and uninsured. Need factors included SPD status (SPD, no SPD), health status (excellent/very good, good, and fair/poor), and functional limitations (yes/no). Personal health practices comprised smoking status (nonsmoker, former smoker, and current smoker), alcohol use (lifetime abstainer, former drinker, and current drinker), physical activity (daily, weekly, no exercise, and unable), and body mass index (BMI). BMI categories were classified into three classifications (underweight/normal $\left(0-25.0 \mathrm{~kg} / \mathrm{m}^{2}\right)$, 
overweight $\left(25.0-30.0 \mathrm{~kg} / \mathrm{m}^{2}\right)$, and obese $\left(30.0-40.0 \mathrm{~kg} / \mathrm{m}^{2}\right)$ ). Finally, external environmental factor was the region of residence (Northeast, Midwest, South, and West region).

2.6. Statistical Analyses. Chi-square tests were used to examine the associations between SPD status and the independent variables in the bivariate analysis. Adjusted logistic regression models were conducted to examine the association between SPD status and ER use. In these regressions, predisposing factors, enabling factors, need factors, personal health practices, and external environmental factors were included as independent variables. Among ER users, separate adjusted logistic regression models were conducted to examine the association between SPD status and the reasons for the ER use in the past 12 months. In these regressions, predisposing factors, enabling factors, need factors, personal health practices, and external environmental factors were included as independent variables.

\section{Results}

3.1. Description of the Study Participants. The characteristics of the study participants $(N=12,869)$ are presented in Table 1. Among adults with multimorbidity, 5.8\% had SPD and 94.2\% did not. More than half of adults with multimorbidity and SPD used the ER in the past 12 months. Nearly a quarter of adults with multimorbidity and no SPD used the ER in the past 12 months. The majority of adults with multimorbidity and SPD (92\%) had functional limitations, whereas $61.3 \%$ of those with multimorbidity and no SPD had functional limitations. About $70 \%$ of adults with multimorbidity and SPD reported fair/poor general health and only $23.7 \%$ of those with multimorbidity and no SPD reported fair/ poor general health. We also found that $31.7 \%$ of adults with multimorbidity and SPD had poor income. In contrast, about $10 \%$ of adults with multimorbidity and no SPD had poor income. Statistically significant differences were also observed in sex, age, race/ethnicity, marital status, education level, health insurance, smoking status, alcohol use, and physical activity between adults with multimorbidity and SPD and those with multimorbidity and no SPD (see Table 1).

3.2. SPD and ER Use. Table 2 displays weighted row percentages, adjusted odds ratios (AOR), and 95\% confidence intervals (CI) from multivariable logistic regression. A statistically significant association $(<0.001)$ between SPD and ER use in the past 12 months was observed. A higher proportion of adults with multimorbidity and SPD reported using ER in the past 12 months compared to those with multimorbidity and no SPD (54.1\% versus $25.2 \%)$. In multivariable logistic regression, after controlling for predisposing factors, enabling factors, need factors, personal health practices, and external environmental factors, the association between SPD and ER use remained statistically significant. Adults with multimorbidity and SPD were $1.61(95 \% \mathrm{CI}=1.26,2.04)$ times as likely to use ER in the past 12 months as those with multimorbidity and no SPD.
3.3. Reasons for the Most Recent ER Visit among ER Users. The majority of ER users (84.2\%) reported seriousness of medical problems as the reason for the most recent ER visit. About $47 \%$ reported doctor's office or clinic was not open and $54.8 \%$ reported lack of access to other providers as the reason for the most recent ER visit. In the bivariate analysis, we found a statistically significant association between SPD and "lack of access to other providers" as the reason for the most recent ER visit. In multivariable logistic regression, after controlling for predisposing factors, enabling factors, need factors, personal health practices, and external environmental factors, there were no statistically significant associations between SPD and the reasons for the most recent ER visit including "lack of access to other providers" (see Table 3). However, a closer examination of the results revealed that without controlling for the age and health insurance in the logistic regression model, adults with multimorbidity, and SPD were 1.42 times $(95 \% \mathrm{CI}=1.03,1.96)$ as likely to report "lack of access to other providers" as the reason for the most recent ER visit compared to those with multimorbidity and no SPD. Once the age and health insurance were entered in the model, the statistical significance of SPD disappeared.

\section{Discussion}

We examined the relationship between SPD and ER use among adults with multimorbidity. Our results revealed that there was a statistically significant relationship between SPD and ER use. Adults with multimorbidity and SPD were more likely to use ER compared to adults with multimorbidity and no SPD. This is consistent with the previous studies showing that SPD is positively associated with ER use among general population $[9,12]$. Several reasons could explain the higher likelihood of ER use among adults with multimorbidity and SPD as compared to those with multimorbidity and no SPD. For example, our study findings indicate that adults with multimorbidity and SPD are at high risk for disability and poor health. This has been documented in published literature as well $[19,20]$. Further, adults with SPD were more likely to avoid visiting a doctor due to the fear of having a serious disease, which may lead to complications that require ER care [21]. Again, lack of mental health-related treatment can lead to ER use. For example, in 2009 , nearly $50 \%$ of US adults with SPD did not receive healthcare services for mental illness [9].

In our study, $54.2 \%$ of adults with multimorbidity and SPD used ER during the past 12 months, which is a cause for concern. Adults with multimorbidity and SPD need care from both chronic condition specialists and mental health specialists [22]. Seeking care in an ER setting may not be effective for these individuals because of limited number of trained ER healthcare professionals who can provide care for mental illness [23]. Given that treatment of chronic conditions in ER is very expensive in the US [24], there is a need to develop health policy programs targeting those with multimorbidity and SPD.

Our findings have implications for promoting collaborative care to reduce ER use. Caring for adults with multimorbidity and SPD is challenging because of competing 
TABLE 1: Characteristics of adults with multimorbidity by serious psychological distress status. National Health Interview Survey, 2015.

\begin{tabular}{|c|c|c|c|c|c|c|c|}
\hline \multirow{3}{*}{ All } & \multicolumn{2}{|c|}{ Total sample } & \multicolumn{2}{|r|}{ SPD } & \multicolumn{2}{|c|}{ No SPD } & \multirow{3}{*}{$P$ value } \\
\hline & $N$ & Wt.\% & $N$ & Wt.\% (Col\%) & $N$ & Wt.\% (Col\%) & \\
\hline & 12,869 & 100.0 & 772 & 5.8 & 12,097 & 94.2 & \\
\hline ER use & & & & & & & $<0.001$ \\
\hline Yes & 3,663 & 26.8 & 412 & 54.1 & 3,251 & 25.2 & \\
\hline No & 9,206 & 73.2 & 360 & 45.9 & 8,846 & 74.8 & \\
\hline \multicolumn{8}{|c|}{ Predisposing factors } \\
\hline Sex & & & & & & & $<0.001$ \\
\hline Women & 7,350 & 53.0 & 509 & 62.8 & 6,841 & 52.4 & \\
\hline Men & 5,519 & 47.0 & 263 & 37.2 & 5,256 & 47.6 & \\
\hline Age in years & & & & & & & $<0.001$ \\
\hline 22-39 years & 1,131 & 10.2 & 108 & 19.0 & 1,023 & 9.7 & \\
\hline $40-49$ years & 1,394 & 12.4 & 144 & 16.8 & 1,250 & 12.1 & \\
\hline 50-64 years & 4,241 & 36.3 & 333 & 44.0 & 3,908 & 35.8 & \\
\hline 65 and older & 6,103 & 41.1 & 187 & 20.2 & 5,916 & 42.3 & \\
\hline Race/ethnicity & & & & & & & 0.012 \\
\hline Hispanic & 1,480 & 10.4 & 139 & 15.3 & 1,341 & 10.1 & \\
\hline Non-Hispanic white & 8,859 & 72.8 & 500 & 69.1 & 8,359 & 73.1 & \\
\hline Non-Hispanic black & 1,889 & 11.9 & 95 & 10.5 & 1,794 & 12.0 & \\
\hline Other non-Hispanic races & 641 & 4.9 & 38 & 5.1 & 603 & 4.9 & \\
\hline \multicolumn{8}{|c|}{ Enabling factors } \\
\hline Marital status & & & & & & & $<0.001$ \\
\hline Married & 6,165 & 63.0 & 279 & 47.5 & 5,886 & 64.0 & \\
\hline Widowed, separated, divorced & 5,135 & 27.5 & 356 & 35.7 & 4,779 & 27.1 & \\
\hline Never & 1,549 & 9.4 & 134 & 16.9 & 1,415 & 8.9 & \\
\hline Education level & & & & & & & $<0.001$ \\
\hline Less than high school & 2,104 & 14.5 & 223 & 29.8 & 1,881 & 13.6 & \\
\hline High school & 3,559 & 27.3 & 210 & 26.9 & 3,349 & 27.5 & \\
\hline Greater than high school & 7,149 & 57.7 & 337 & 43.2 & 6,812 & 58.9 & \\
\hline Poverty status & & & & & & & $<0.001$ \\
\hline$<100 \%$ FPL & 1,945 & 11.1 & 295 & 31.5 & 1,650 & 9.9 & \\
\hline $100-<200 \%$ & 2,748 & 18.5 & 218 & 27.2 & 2,530 & 17.9 & \\
\hline $200-<400 \%$ & 3,474 & 26.5 & 153 & 24.4 & 3,321 & 26.6 & \\
\hline$\geq 400 \%$ & 3,848 & 37.0 & 74 & 12.1 & 3,774 & 38.6 & \\
\hline Missing & 854 & 6.9 & 32 & 4.8 & 822 & 7.0 & \\
\hline Health insurance & & & & & & & $<0.001$ \\
\hline Insured & 12,228 & 95.0 & 691 & 86.6 & 11,537 & 95.5 & \\
\hline Uninsured & 641 & 5.0 & 81 & 13.4 & 560 & 4.5 & \\
\hline \multicolumn{8}{|c|}{ Need factors } \\
\hline Perceived general health & & & & & & & $<0.001$ \\
\hline Excellent/very good & 4,737 & 39.0 & 76 & 11.9 & 4,661 & 40.6 & \\
\hline Good & 4,486 & 34.7 & 158 & 19.2 & 4,328 & 35.7 & \\
\hline Fair/Poor & 3,642 & 26.3 & 538 & 68.9 & 3,104 & 23.7 & \\
\hline Functional limitations & & & & & & & $<0.001$ \\
\hline Yes & 8,547 & 63.0 & 715 & 92.0 & 7,832 & 61.3 & \\
\hline No & 4,312 & 36.9 & 57 & 8.0 & 4,255 & 38.7 & \\
\hline \multicolumn{8}{|c|}{ Personal health practices } \\
\hline Body mass index & & & & & & & 0.008 \\
\hline Underweight /normal & 3,223 & 24.0 & 197 & 26.1 & 3,026 & 23.9 & \\
\hline Overweight & 4,246 & 33.3 & 193 & 26.3 & 4,053 & 33.8 & \\
\hline Obese & 5,076 & 39.8 & 354 & 42.9 & 4,722 & 39.6 & \\
\hline Missing & 324 & 2.8 & 28 & 4.7 & 296 & 2.7 & \\
\hline
\end{tabular}


TABLE 1: Continued.

\begin{tabular}{|c|c|c|c|c|c|c|c|}
\hline \multirow{3}{*}{ All } & \multicolumn{2}{|c|}{ Total sample } & \multicolumn{2}{|c|}{ SPD } & \multicolumn{2}{|c|}{ No SPD } & \multirow{3}{*}{$P$ value } \\
\hline & $N$ & Wt.\% & $N$ & Wt.\% (Col\%) & $N$ & Wt.\% (Col\%) & \\
\hline & 12,869 & 100.0 & 772 & 5.8 & 12,097 & 94.2 & \\
\hline Smoking status & & & & & & & $<0.001$ \\
\hline Nonsmoker & 6,521 & 51.7 & 285 & 37.4 & 6,236 & 52.6 & \\
\hline Former smoker & 4,210 & 32.8 & 166 & 20.5 & 4,044 & 33.6 & \\
\hline Current Smoker & 2,126 & 15.4 & 321 & 42.1 & 1,805 & 13.8 & \\
\hline Alcohol use & & & & & & & $<0.001$ \\
\hline Lifetime abstainer & 2,581 & 17.9 & 143 & 18.2 & 2,438 & 18.0 & \\
\hline Former drinker & 3,088 & 22.9 & 249 & 32.1 & 2,839 & 22.4 & \\
\hline Current drinker & 7,125 & 58.7 & 376 & 49.7 & 6,749 & 59.6 & \\
\hline Physical activity & & & & & & & $<0.001$ \\
\hline Daily & 623 & 4.9 & 25 & 2.7 & 598 & 5.1 & \\
\hline Weekly & 2,825 & 24.8 & 75 & 11.2 & 2,750 & 25.8 & \\
\hline No exercise & 8,811 & 66.2 & 586 & 75.3 & 8,225 & 65.9 & \\
\hline Unable & 565 & 3.7 & 82 & 10.7 & 483 & 3.3 & \\
\hline \multicolumn{8}{|c|}{ External environmental factors } \\
\hline Region of residence & & & & & & & 0.615 \\
\hline Northeast & 2,197 & 17.6 & 132 & 15.1 & 2,065 & 17.8 & \\
\hline Midwest & 2,768 & 23.2 & 155 & 23.9 & 2,613 & 23.2 & \\
\hline South & 4,603 & 38.6 & 287 & 40.6 & 4,316 & 38.5 & \\
\hline West & 3,301 & 20.6 & 198 & 20.4 & 3,103 & 20.6 & \\
\hline
\end{tabular}

Note. Based on 12,869 adults aged over 21 years having two or more physical diseases with and without serious psychological distress (SPD). SPD was defined as a score of 13 or greater on the K6. SPD: serious psychological distress; ER: emergency room; Wt.: weighted; FPL: federal poverty line.

demands and shifting priorities [25]; their care may be compromised due to lack of care coordination between the mental health and physical health providers [22]. Under feefor-service healthcare systems, the lack of communication and coordination of care between mental health and physical health professionals has been well documented [22]. Such lack of coordination may lead to higher ER use among those with multimorbidity and SPD. To address these issues, collaborative care model may help in managing adults with multimorbidity and SPD. Numerous studies have provided evidence that collaborative care interventions can lead to better outcomes for those with physical and mental illnesses $[26,27]$. One study evaluating the role of collaborative care for individuals with chronic diseases and depression found that individuals who received collaborative care had better chronic disease outcomes than those who received usual care [26].

Among adults with multimorbidity, the majority of ER users (84.2\%) reported seriousness of medical problems as the reason for using ER, which has implications for all adults with multimorbidity. Complexity and seriousness of medical problems among those with multimorbidity are well documented [1]. To prevent ER use among those with multimorbidity in general, prevention strategies may need to be emphasized. For example, for many of the chronic conditions included in our list (e.g., heart disease, diabetes, COPD, and stroke), complications can be easily avoided through modification of life-style risk factors. According to the Centers for Disease Control and Prevention, four modifiable health risk behaviors-lack of exercise, poor nutrition, tobacco use, and excessive alcohol use-have accounted for much of the complications related to chronic disease [28]. These factors may also be relevant for those with multimorbidity. Also, these four modifiable risk factors have been shown to increase ER use [29-31]. Therefore, to reduce ER use among those with multimorbidity, secondary prevention strategies need to target these four modifiable risk factors [28].

Our study had both strengths and limitations. One of the strengths was that the study used nationally representative data for adults with multimorbidity. Furthermore, the association between SPD and ER use was examined after controlling for predisposing, enabling, need, personal health practices, and environmental factors. Another strength was that the reasons behind ER use were investigated. The study findings have to be interpreted in the context of its limitations. We adopted a cross-sectional study design, which can only suggest associations. All data were self-reported and may be subject to recall bias. The definition of multimorbidity was limited. We did not examine the intensity of ER use (i.e., number of ER visits). We only assessed the reasons for the most recent ER visit.

\section{Conclusion}

The present study found that adults with multimorbidity and SPD were more likely to use ER as compared to those with multimorbidity and no SPD. Given the high risk of SPD among adults with multimorbidity, routine screening for 
TABLE 2: Weighted row percentages, adjusted odds ratios, and $95 \%$ confidence intervals of serious psychological distress from logistic regressions on ER use in the past 12 months. National Health Interview Survey, 2015.

\begin{tabular}{|c|c|c|c|c|}
\hline & Wt.\% & AOR & $95 \% \mathrm{CI}$ & $P$ value \\
\hline \multicolumn{5}{|c|}{ Predisposing factors } \\
\hline \multicolumn{5}{|l|}{ Sex } \\
\hline Women & 27.9 & 0.98 & {$[0.86,1.10]$} & 0.685 \\
\hline Men (Ref.) & 25.6 & & & \\
\hline \multicolumn{5}{|l|}{ Age in years } \\
\hline $22-39$ & 39.3 & 2.70 & {$[2.21,3.30]$} & $<0.001$ \\
\hline $40-49$ & 27.0 & 1.35 & {$[1.13,1.62]$} & 0.001 \\
\hline $50-64$ & 25.9 & 1.14 & {$[1.00,1.30]$} & 0.058 \\
\hline$\geq 65$ (Ref.) & 24.5 & & & \\
\hline \multicolumn{5}{|l|}{ Race/ethnicity } \\
\hline Hispanic & 29.6 & 0.93 & {$[0.77,1.13]$} & 0.487 \\
\hline Non-Hispanic black & 35.1 & 1.34 & {$[1.15,1.56]$} & $<0.001$ \\
\hline Other non-Hispanic races & 19.0 & 0.66 & {$[0.51,0.84]$} & 0.001 \\
\hline Non-Hispanic white (Ref.) & 25.6 & & & \\
\hline \multicolumn{5}{|c|}{ Enabling factors } \\
\hline \multicolumn{5}{|l|}{ Marital status } \\
\hline Married & 24.0 & 1.08 & {$[0.89,1.30]$} & 0.448 \\
\hline Widowed, separated, divorced & 31.0 & 1.18 & {$[0.97,1.42]$} & 0.090 \\
\hline Never (Ref.) & 33.7 & & & \\
\hline \multicolumn{5}{|l|}{ Education level } \\
\hline High school & 28.8 & 0.92 & {$[0.76,1.13]$} & 0.436 \\
\hline Greater than high school & 23.4 & 0.93 & {$[0.77,1.13]$} & 0.464 \\
\hline Less than high school (Ref.) & 36.8 & & & \\
\hline \multicolumn{5}{|l|}{ Poverty status } \\
\hline $100-<200 \%$ & 34.9 & 0.89 & {$[0.74,1.06]$} & 0.203 \\
\hline $200-<400 \%$ & 26.7 & 0.72 & {$[0.59,0.87]$} & 0.001 \\
\hline$\geq 400 \%$ & 18.3 & 0.65 & {$[0.53,0.80]$} & 0.000 \\
\hline Missing & 26.1 & 0.83 & {$[0.63,1.08]$} & 0.169 \\
\hline$<100 \%$ FPL (Ref.) & 42.9 & & & \\
\hline \multicolumn{5}{|l|}{ Health insurance } \\
\hline Insured & 26.4 & 1.00 & {$[0.78,1.28]$} & 0.999 \\
\hline Uninsured (Ref.) & 35.7 & & & \\
\hline \multicolumn{5}{|c|}{ Need factors } \\
\hline \multicolumn{5}{|l|}{ SPD status } \\
\hline SPD & 54.1 & 1.61 & {$[1.26,2.04]$} & $<0.001$ \\
\hline No SPD (Ref.) & 25.2 & & & \\
\hline \multicolumn{5}{|l|}{ Perceived general health } \\
\hline Excellent/very good & 15.8 & 0.40 & {$[0.34,0.48]$} & $<0.001$ \\
\hline Good & 26.1 & 0.62 & {$[0.54,0.71]$} & $<0.001$ \\
\hline Fair/poor (Ref.) & 44.1 & & & \\
\hline \multicolumn{5}{|l|}{ Functional limitations } \\
\hline No & 16.0 & 0.55 & {$[0.48,0.64]$} & $<0.001$ \\
\hline Yes (Ref.) & 33.2 & & & \\
\hline \multicolumn{5}{|c|}{ Personal health practices } \\
\hline \multicolumn{5}{|l|}{ Body mass index } \\
\hline Underweight/normal & 28.6 & 1.18 & {$[1.02,1.38]$} & 0.028 \\
\hline Overweight & 22.9 & 0.92 & {$[0.81,1.05]$} & 0.231 \\
\hline Missing & 23.7 & 0.76 & {$[0.54,1.09]$} & 0.133 \\
\hline Obese (Ref.) & 29.3 & & & \\
\hline \multicolumn{5}{|l|}{ Smoking status } \\
\hline Nonsmoker & 23.5 & 0.77 & {$[0.66,0.91]$} & 0.001 \\
\hline Former smoker & 26.4 & 0.88 & {$[0.75,1.04]$} & 0.145 \\
\hline Current smoker (Ref.) & 38.7 & & & \\
\hline
\end{tabular}


TABLE 2: Continued.

\begin{tabular}{|c|c|c|c|c|}
\hline & Wt.\% & $\mathrm{AOR}$ & $95 \%$ CI & $P$ value \\
\hline \multicolumn{5}{|l|}{ Alcohol use } \\
\hline Lifetime abstainer & 29.3 & 1.10 & {$[0.92,1.31]$} & 0.281 \\
\hline Former drinker & 32.6 & 1.16 & {$[1.00,1.34]$} & 0.047 \\
\hline Current drinker (Ref.) & 23.9 & & & \\
\hline \multicolumn{5}{|l|}{ Physical activity } \\
\hline Daily & 19.3 & 0.75 & {$[0.56,1.01]$} & 0.059 \\
\hline Weekly & 19.2 & 0.87 & {$[0.74,1.02]$} & 0.082 \\
\hline Unable & 47.4 & 1.51 & {$[1.13,2.01]$} & 0.005 \\
\hline No exercise (Ref.) & 29.0 & & & \\
\hline \multicolumn{5}{|c|}{ External environmental factors } \\
\hline \multicolumn{5}{|l|}{ Region of residence } \\
\hline Northeast & 26.2 & 1.03 & {$[0.87,1.23]$} & 0.714 \\
\hline Midwest & 28.3 & 1.08 & {$[0.93,1.26]$} & 0.306 \\
\hline South & 27.1 & 0.95 & {$[0.83,1.08]$} & 0.414 \\
\hline West (Ref.) & 25.1 & & & \\
\hline
\end{tabular}

Note. Based on 12,869 adults aged over 21 years having two or more physical diseases with and without serious psychological distress (SPD). SPD was defined as a score of 13 or greater on the K6. Wt.: weighted; AOR: adjusted odds ratio; CI: confidence interval; Ref.: reference group; SPD: serious psychological distress; FPL: federal poverty line.

TABLE 3: Weight row percentages, adjusted odds ratios, and 95\% confidence intervals of serious psychological distress from separate logistic regressions on reasons of the recent ER use in the past 12 months. Adults with multimorbidity and ER use. National Health Interview Survey, 2015.

\begin{tabular}{lcccc}
\hline SPD status & Wt.\% & AOR & $95 \%$ CI & $P$ value \\
\hline \multicolumn{5}{c}{ Seriousness of medical problem } \\
SPD & 85.6 & 1.03 & {$[0.65,1.63]$} & 0.888 \\
No SPD (Ref.) & 84.0 & & \\
\hline \multicolumn{5}{c}{ Doctor's office or clinic was not open } \\
SPD & 44.9 & 0.93 & {$[0.67,1.29]$} & 0.676 \\
No SPD (Ref.) & 46.4 & & \\
\hline \multicolumn{5}{c}{ Lack of access to other providers } \\
SPD & 67.0 & 1.27 & {$[0.91,1.76]$} & 0.165 \\
No SPD (Ref.) & 53.3 & & \\
\hline
\end{tabular}

Note. Based on 3,663 adults aged over 21 years having two or more physical diseases with and without serious psychological distress (SPD). SPD was defined as a score of 13 or greater on the K6. Adjusted model included sex, age, race/ethnicity, marital status, education level, poverty status, perceived general health, functional limitations, body mass index $\left(\mathrm{kg} / \mathrm{m}^{2}\right)$, smoking status, alcohol use, physical activity, and region of residence. Wt.: weighted; AOR: adjusted odds ratio; CI: confidence interval; Ref.: reference group; SPD: serious psychological distress.

SPD may be needed. Also, collaborative care model may be needed to minimize the risk of ER use among those with multimorbidity and SPD.

\section{Conflicts of Interest}

The authors declare that there are no conflicts of interest regarding the publication of this article.

\section{Acknowledgments}

The authors would like to thank Mr. Michael Denney for his contributions in revising some parts of the final drafts. The project described was supported by the National Institute of General Medical Sciences (U54GM104942).

\section{References}

[1] C. M. Boyd and M. Fortin, "Future of multimorbidity research: how should understanding of multimorbidity inform health system design?” Public Health Reviews, vol. 32, no. 2, pp. 451474, 2010.

[2] B. W. Ward, J. S. Schiller, and R. A. Goodman, "Multiple chronic conditions among us adults: a 2012 update," Preventing Chronic Disease, vol. 11, no. 4, Article ID 130389, 2014.

[3] R. Palladino, J. T. Lee, M. Ashworth, M. Triassi, and C. Millett, "Associations between multimorbidity, healthcare utilisation and health status: Evidence from 16 European countries," Age and Ageing, vol. 45, no. 3, pp. 431-435, 2016.

[4] W. Yu, A. Ravelo, T. H. Wagner, and P. G. Barnett, "The relationships among age, chronic conditions, and healthcare costs," American Journal of Managed Care, vol. 10, no. 12, pp. 909-916, 2004.

[5] A. Ryan, E. Wallace, P. O’Hara, and S. M. Smith, "Multimorbidity and functional decline in community-dwelling adults: A systematic review," Health and Quality of Life Outcomes, vol. 13, no. 1, 2015.

[6] M. Fortin, L. Lapointe, C. Hudon, A. Vanasse, A. L. Ntetu, and D. Maltais, "Multimorbidity and quality of life in primary care: a systematic review," Health and Quality of Life Outcomes, vol. 2, article 51, 2004.

[7] J. A. Swartz and I. Jantz, "Association between nonspecific severe psychological distress as an indicator of serious mental 
illness and increasing levels of medical multimorbidity," American Journal of Public Health, vol. 104, no. 12, pp. 2350-2358, 2014.

[8] M. Fortin, G. Bravo, C. Hudon, L. Lapointe, M.-F. Dubois, and J. Almirall, "Psychological distress and multimorbidity in primary care," Annals of Family Medicine, vol. 4, no. 5, pp. 417422, 2006.

[9] E. L. Stockbridge, F. A. Wilson, and J. A. Pagán, "Psychological distress and emergency department utilization in the United states: evidence from the Medical Expenditure Panel Survey," Academic Emergency Medicine, vol. 21, no. 5, pp. 510-519, 2014.

[10] P. Shelton, M. A. Sager, and C. Schraeder, "The Community Assessment Risk Screen (CARS): Identifying elderly persons at risk for hospitalization or emergency department visit," American Journal of Managed Care, vol. 6, no. 8, pp. 925-933, 2000.

[11] M. N. Shah, P. J. Rathouz, and M. H. Chin, "Emergency department utilization by noninstitutionalized elders," Academic Emergency Medicine, vol. 8, no. 3, pp. 267-273, 2001.

[12] M.-T. Lin, J. F. Burgess Jr., and K. Carey, "The association between serious psychological distress and emergency department utilization among young adults in the USA," Social Psychiatry and Psychiatric Epidemiology, vol. 47, no. 6, pp. 939947, 2012.

[13] R. Andersen and J. F. Newman, "Societal and individual determinants of medical care utilization in the United States," The Milbank Quarterly, vol. 83, no. 4, pp. 1-28, 2005.

[14] National Center for Health Statistics, "National Health Interview Survey (NHIS) survey description," ftp://ftp.cdc.gov/pub/ Health_Statistics/NCHS/Dataset_Documentation/NHIS/2015/ srvydesc.pdf.

[15] R. A. Goodman, S. F. Posner, E. S. Huang, A. K. Parekh, and H. K. Koh, "Defining and measuring chronic conditions: imperatives for research, policy, program, and practice," Preventing Chronic Disease, vol. 10, Article ID 120239, 2013.

[16] R. M. Gindi, L. I. Black, and R. A. Cohen, "Reasons for Emergency Room Use Among U.S. Adults Aged 18-64: National Health Interview Survey, 2013 and 2014," National health statistics reports, no. 90, pp. 1-16, 2016.

[17] R. C. Kessler, J. G. Green, M. J. Gruber et al., "Screening for serious mental illness in the general population with the K6 screening scale: results from the WHO World Mental Health (WMH) survey initiative," International Journal of Methods in Psychiatric Research, vol. 19, supplement 1, pp. 4-22, 2010.

[18] L. A. Pratt, "Serious psychological distress, as measured by the K6, and mortality," Annals of Epidemiology, vol. 19, no. 3, pp. 202-209, 2009.

[19] M. Shih and P. A. Simon, "Health-related quality of life among adults with serious psychological distress and chronic medical conditions," Quality of Life Research, vol. 17, no. 4, pp. 521-528, 2008.

[20] D. Rai, K. Kosidou, M. Lundberg, R. Araya, G. Lewis, and C. Magnusson, "Psychological distress and risk of long-term disability: Population-based longitudinal study," Journal of Epidemiology and Community Health, vol. 66, no. 7, pp. 586-592, 2012.

[21] J. Ye, R. Shim, and G. Rust, "Health care avoidance among people with serious psychological distress: Analyses of 2007 Health Information National Trends Survey," Journal of Health Care for the Poor and Underserved, vol. 23, no. 4, pp. 1620-1629, 2012.

[22] Institute of Medicine Committee on Crossing the Quality Chasm, Adaptation to Mental H, Addictive D. The National
Academies Collection: Reports funded by National Institutes of Health. Improving the Quality of Health Care for Mental and Substance-Use Conditions: Quality Chasm Series. Washington (DC): National Academies Press (US) National Academy of Sciences, 2006.

[23] V. Alakeson, N. Pande, and M. Ludwig, "A plan to reduce emergency room 'Boarding" of psychiatric patients," Health Affairs, vol. 29, no. 9, pp. 1637-1642, 2010.

[24] N. Caldwell, T. Srebotnjak, T. Wang, and R. Hsia, “"“How Much Will I Get Charged for This?" Patient Charges for Top Ten Diagnoses in the Emergency Department," PLOS ONE, vol. 8, no. 2, Article ID e55491, 2013.

[25] R. L. Morris, C. Sanders, A. P. Kennedy, and A. Rogers, "Shifting priorities in multimorbidity: A longitudinal qualitative study of patient's prioritization of multiple conditions," Chronic Illness, vol. 7, no. 2, pp. 147-161, 2011.

[26] W. J. Katon, E. H. B. Lin, M. Von Korff et al., "Collaborative care for patients with depression and chronic illnesses," The New England Journal of Medicine, vol. 363, no. 27, pp. 2611-2620, 2010.

[27] S. Gilbody, P. Bower, J. Fletcher, D. Richards, and A. J. Sutton, "Collaborative care for depression: A cumulative meta-analysis and review of longer-term outcomes," Archives of Internal Medicine, vol. 166, no. 21, pp. 2314-2321, 2006.

[28] The Power of Prevention, https://www.cdc.gov/chronicdisease/ pdf/2009-Power-of-Prevention.pdf.

[29] D. Indig, M. Eyeson-Annan, J. Copeland, and K. M. Conigrave, "The effects of alcohol consumption, psychological distress and smoking status on emergency department presentations in New South Wales, Australia," BMC Public Health, vol. 7, article no. 46, 2007.

[30] F. Wang, T. McDonald, B. Reffitt, and D. W. Edington, "BMI, physical activity, and health care utilization/costs among medicare retirees," Obesity Research, vol. 13, no. 8, pp. 1450-1457, 2005.

[31] D. W. Ford, T. J. Hartman, C. Still et al., "Diet quality and body mass index are associated with health care resource use in rural older adults," Journal of the Academy of Nutrition and Dietetics, vol. 114, no. 12, pp. 1932-1938, 2014. 


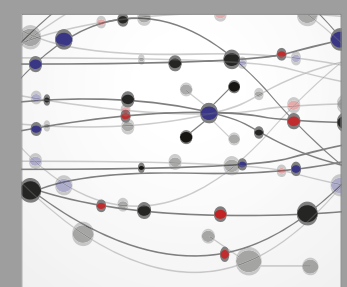

The Scientific World Journal
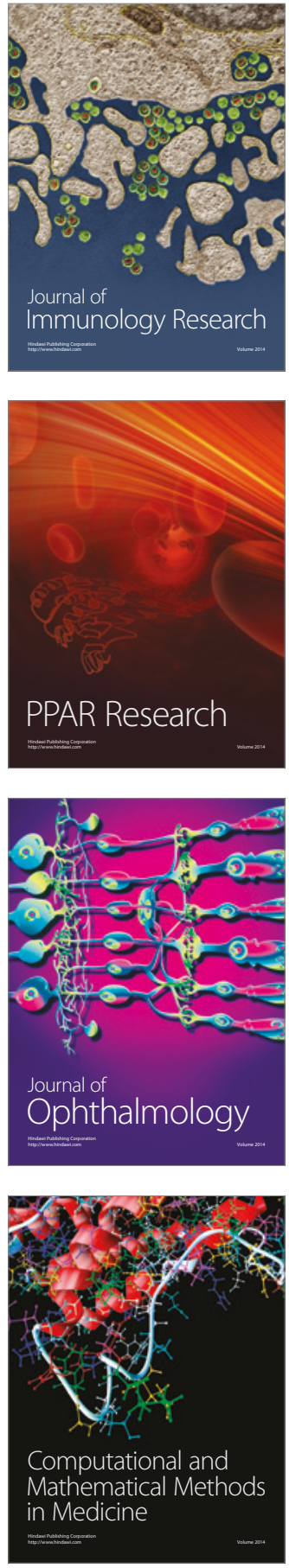

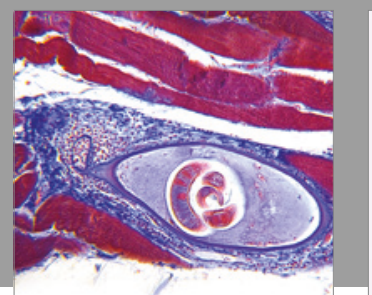

Gastroenterology Research and Practice
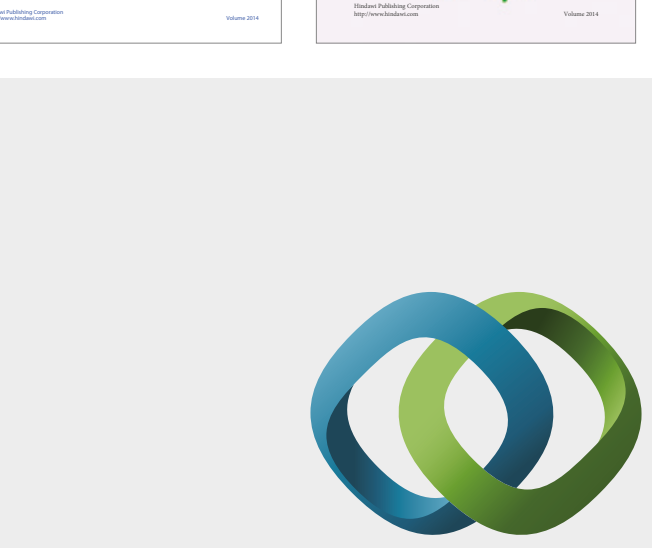

\section{Hindawi}

Submit your manuscripts at

https://www.hindawi.com
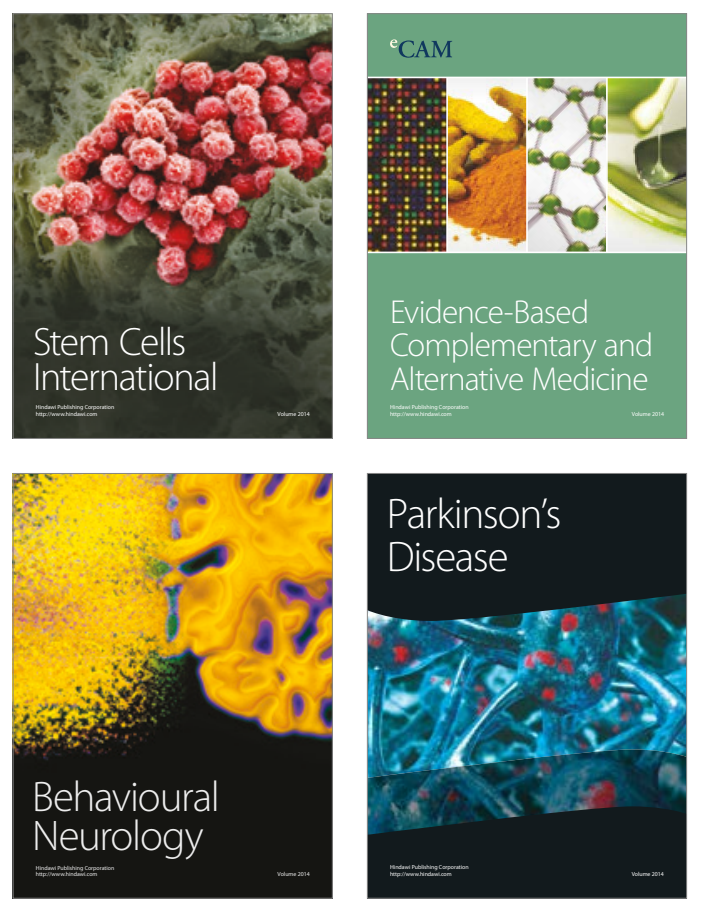
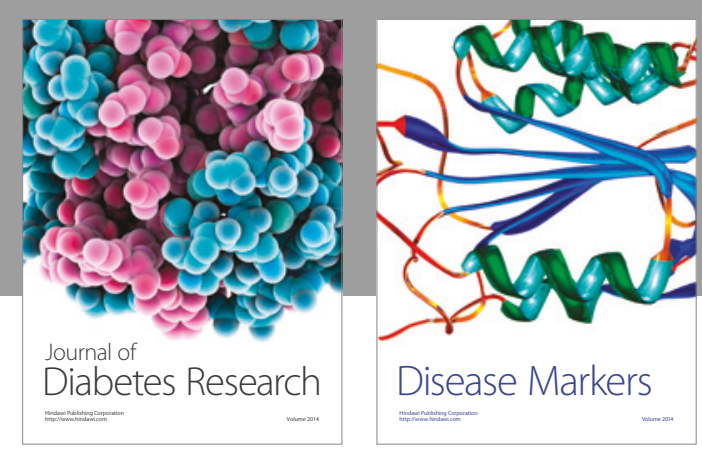

Disease Markers
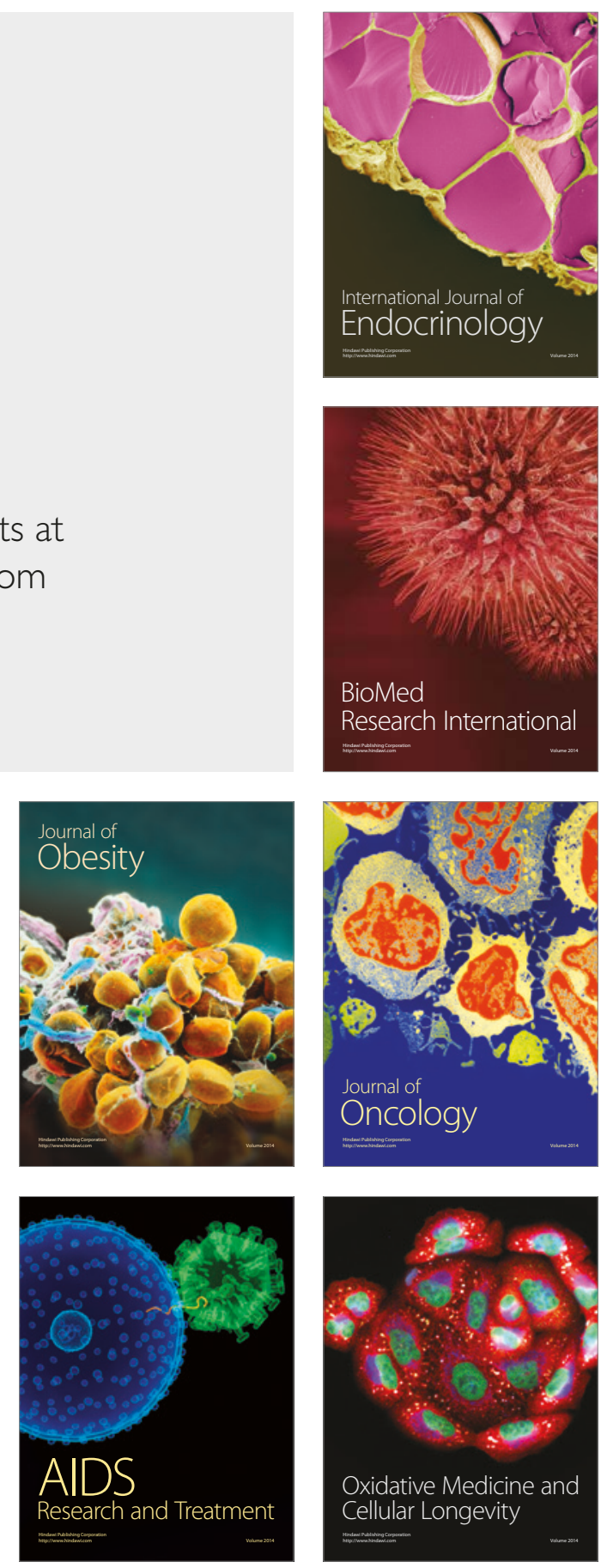